\title{
AS PERSPECTIVAS DO ATO DE AVALIAR EM SALA DE AULA E A AVALIAÇÃO SISTEMÁTICA NA REDE MUNICIPAL DE PORTO VELHO EM RAZÃO DO SAEB
}

\author{
PERSPECTIVES OF THE ACT OF CLASSROOM EVALUATION AND SYSTEMATIC \\ EVALUATION IN THE MUNICIPAL NETWORK OF PORTO VELHO IN LIGHT OF SAEB
}

\author{
Rosenilda Caetano ${ }^{1}$ \\ Wendell Fiori de Faria ${ }^{2}$ \\ Josineide Macena da Silva ${ }^{3}$
}

${ }^{1}$ Mestranda do Programa de Mestrado em Educação pela Universidade Federal de Rondônia. Graduada em Pedagogia pela Uniron.

${ }^{2}$ Professor adjunto IV da Fundação Universidade Federal de Rondônia - UNIR; Doutor em Educação pela Universidade Federal Fluminense; Atuando na graduação e no Programa de Pós-Graduação Mestrado Acadêmico em educação MEDUC; Membro do Grupo de Pesquisa Práxis. Contato: professorfiori@gmail.com

${ }^{3}$ Mestranda em Educação pela Universidade Federal de Rondônia. Especialista em Coordenação Pedagógica pela Universidade Federal de Rondônia. Graduada em Pedagogia pela Universidade Federal de Rondônia.
Recebido em novembro de 2018 Aceito em março de 2020
CAETANO, R.; FARIA, W. F. de; SILVA, J. M. da. As perspectivas do ato de avaliar em sala de aula e a avaliação sistemática na rede municipal de Porto Velho em razão do Saeb. Akrópolis, Umuarama, v. 28, n. 2, p. 145-154, jul./dez. 2020.

DOI: 10.25110/akropolis.v28i2.8116

Resumo: $O$ presente artigo visa a realizar uma reflexão sobre conceituação de avaliação e alguns de seus aspectos históricos no Brasil, mediante a partir de uma revisão bibliográfica. Ressalta-se que no âmbito educacional em algumas situações executa-se o ato de avaliar com a única finalidade de classificar o ensino, o aluno e o trabalho professoral. Além disso, desde o ano de 2007, o Governo Federal implantou a avaliação sistêmica aplicada para os estudantes de alguns anos escolares do Ensino Fundamental e Ensino Médio, tendo como meta verificar a aprendizagem e apresentar o Índice de Desenvolvimento da Educação Básica (IDEB) de todo território brasileiro. Sendo assim, buscou-se respostas para a respectiva problemática: como a avaliação sistêmica na Rede Municipal de Ensino de Porto Velho poderá contribuir para melhoria da aprendizagem de modo a subsidiar a qualidade da prática pedagógica para os alunos? O objetivo geral deste artigo consistiu em identificar algumas contribuições da avaliação sistêmica para melhoria da aprendizagem na Rede Municipal de Ensino de Porto Velho a partir do ano de 2017 na responsabilidade da Secretaria Municipal de Educação. A metodologia utilizada pautou-se no levantamento de bibliografias com abordagem qualitativa sobre a temática. Conclui-se que existe a necessidade de repensar as práticas avaliativas na escola, assim como no sistema municipal e federal de ensino, pois, há evidências que o estudante na contemporaneidade apresenta um novo perfil a ser formado diante do advento tecnológico e das inúmeras questões socioemocionais, o que remete a importância de também avaliar o estudante em aspectos intelectuais, físicos, culturais e emocionais.

Palavras-chave: Avaliação; Aprendizagem; Qualidade do ensino; SAEB.

ABStRAct: This article aims at reflecting on the conceptualization of evaluation and historical aspects in Brazil through a historical-critical approach in a literature review. It is noteworthy that in the educational context, in some situations, the act of evaluating is performed with the sole purpose of classifying teaching, students, and the work of teaching. In addition, since 2007, the Federal Government has implemented the systemic assessment applied to students of some elementary and high school years, with the purpose of verifying learning and presenting the Basic Education Development Index (IDEB) throughout the Brazilian 
territory. Therefore, this article seeks answers to the following problem: how can systemic assessment in the Porto Velho Municipal Education Network contribute to improving learning in order to subsidize the quality of pedagogical practice for students? The general objective of this study was to identify the contributions of the systemic assessment to improve learning in the Municipal Education Network of Porto Velho from 2017 onwards under the responsibility of the Municipal Department of Education. It used a methodology based on the literature survey with a qualitative approach on the theme. It can be concluded that there is a need to rethink the evaluation practices at school, as well as in the municipal and federal education system, since there is evidence that the contemporary student has a new profile to be formed in the face of technological advances and countless socio-emotional issues, which refers to the importance of also evaluating the student in intellectual, physical, cultural and emotional aspects.

KEYwORDS: Evaluation; Learning; Quality of teaching; SAEB.

\section{INTRODUÇÃO}

Vive-se neste momento a era do consumismo, das urgências e emergências, das soluções imediatas conforme apontado por Bauman (1999). Dentro desse contexto modificado o âmbito educacional sinaliza para um novo cenário no qual existe a necessidade de rupturas de paradigmas, principalmente no que tange aos processos metodológicos e avaliativos.

Fazem-se necessárias novas formas gerenciais do processo de aprendizagem que comunguem com a globalização e com as tecnologias criadas para consubstanciar o aprender e a impulsionar a criticidade e reflexão na formação identitária dos estudantes para atuar em seus projetos de vida e protagonismo juvenil para o alcançar da autonomia, competências e habilidades de forma individual ou coletiva.

Assim, a avaliação requer a compreensão que ela engloba as dimensões intelectuais, culturais, físicas e emocionais em todos os níveis educacionais no sentido de viabilizar respostas sobre a assimilação dos saberes ministrados em sala de aula pelo professorado.

No contexto educacional, influencia a ação educativa, dada sua complexidade, haja vista as diferentes formas de interpretá-la e concebê-la, mas é claramente compreendida como um dos elementos da regulação do ensino.

Para tanto, os professores precisam embasar as práticas pedagógicas que contribuam para formar nos estudantes as premissas da qualidade educacional mediante processos avaliativos diferenciados. $O$ ato de avaliar a aprendizagem é o retorno da assimilação do conhecimento e do desenvolvimento cognitivo, social, cultural, emocional etc.

Além disso, a avaliação é assegurada na Lei de Diretrizes e Bases da Educação $n^{\circ}$ 9394/96, promulgada em 20 de dezembro de 1996, nos artigos 13 e 24, quando trata das incumbências dos professores ao avaliar, e dos critérios do rendimento escolar.

Diante do exposto, buscou-se respostas para o problema deste trabalho pautado em: como a avaliação sistêmica na Rede Municipal de Ensino de Porto Velho poderá contribuir para melhoria da aprendizagem de modo a subsidiar a qualidade da prática pedagógica para os alunos?

O objetivo geral consistiu em identificar as contribuições da avaliação sistêmica para melhoria da aprendizagem na Rede Municipal de Ensino de Porto Velho a partir do ano de 2017, sendo de responsabilidade da Secretaria Municipal de Educação.

O tema abordado, portanto, é um grande desafio educacional, pois o processo avaliativo para o educando deve romper com a fragmentação, e a relação entre o tradicional e o novo formato promulgado para atender o processo formativo integral, autônomo e protagonista.

\section{A HISTORICIDADE DO ATO DE AVALIAR A APRENDIZAGEM NA EDUCAÇÃO DO BRASIL}

A política educacional do Brasil após a abertura política em 1.985 buscou priorizar a universalização do acesso ao ensino fundamental, em cumprimento à exigência estabelecida pela Constituição Federal de 1988, que determinou a obrigatoriedade desse nível de ensino.

A Constituição assegura em seu art. 22, inciso XXIV que a educação é direito de todos e dever do Estado e da família, devendo ser promovida e incentivada com a colaboração da sociedade, visando ao pleno desenvolvimento da pessoa, seu preparo para o exercício da cidadania e sua qualificação para o trabalho (BRASIL, 1988).

Além do acesso é preciso ofertar um 
ensino com qualidade e novas formas de pensar a avaliação e ao mesmo tempo refletir sobre a origem deste processo.

Inicialmente, no Brasil colônia no perfilar da pedagogia Jesuítica originada da teologia católica dos séculos XVI e XVII, criada para atender as necessidades da sociedade burguesa, visou uma hegemonia católica, na qual admitiam a subjetividade necessária para produzir a ciência, mas sob controle (LUCKESI, 2011, p. 242).

Seguidamente, houve-se o mecanismo de avaliar por meio da obra A Didática Magna, publicada em 1632, por Jan Amos Komenský (João Amós Comênio), bispo protestante e primeiro autor de um livro sobre didática, sua teoria defendia uma ideia de metodologia para a prática de ensino, propondo pela primeira vez na história do ensino o uso de objetos ou coisas reais para ensinar, tendo o empirismo como base do conhecimento.

Tanto a pedagogia Jesuítica, como a pedagogia Comeniana, tinham suas bases pedagógicas que delimitavam aos professores como os alunos deveriam ser controlados a qualquer custo e que, se necessário, usassem a ameaça e o medo.

Entretanto, a partir da Independência, D. Pedro I, filho de D. João VI, buscou-se dar melhoramentos para disseminação da instrução pública com a criação de algumas escolas para ensinar conforme o método Lancaster como o primeiro método de ensino a ser utilizado no Brasil por meio da Lei 15 de outubro de 1827 , conhecida como a primeira Lei Geral para a Instrução Pública da independência até 1946.

Sua composição assegurou 17 artigos, na qual o método oficial era para o ensino das escolas de primeiras letras, denominado Método do Ensino Mútuo e de Lancaster. Segundo Neves (2007, p. 2), um método pedagógico formulado, na Inglaterra, no início do século $\mathrm{XIX}$, no qual os soldados foram escolhidos para serem os primeiros a serem instruídos pelo Método para, posteriormente, se tornarem mestres lancasterianos.

Lancaster amparou seu método no ensino oral, no uso refinado e constante da repetição e, principalmente, na memorização, porque acreditava que esta inibia a preguiça, a ociosidade, e aumentava o desejo pela quietude. Em face desta opção metodológica ele não esperava que os alunos tivessem originalidade ou elucubração intelectual na atividade pedagógica, mas disciplinarização mental e física (NEVES, 2003).

O referido método não apresentava um modelo específico para avaliar, pois o que se tinha era uma disciplina rígida em que incluía uma conduta obediente por parte do estudante em que deveria aceitar as ordens, sem questionamentos como fator de controle e hierarquização em que a classe pobre, principalmente, recebia o mínimo dessa instrução, cabendo o favorecimento para a classe dominante.

O governo imperial atribuía às províncias "[...] a responsabilidade direta pelo ensino primário e secundário, através das leis e decretos que vão sendo criados e aprovados, sem que seja aplicado, pois não existiam escolas e poucos eram os professores" (NASCIMENTO, 2004, p. 95).

Com o perpassar do tempo, chegamos no período de 1930 a 1945, no qual se estabeleceu o período tyleriano da avaliação da aprendizagem, definido por Ralph Tyler, um educador norte americano que defendeu a ideia de uma avaliação centrada nos objetivos definidos pelo professor, denominada "ensino por objetivos".

No Brasil as contribuições de Tyler chegam na década de 1930, com o termo "avaliação da aprendizagem escolar". Todavia, neste momento no território brasileiro as avaliações eram feitas com caráter admissional para o egresso no ensino secundário.

Ressalta-se que a supracitada seleção operava como estratificação social da população, pois o exame favorecia sistematicamente os que pertenciam ao nível mais elevado das classes predominantes, e desfavorecia a população pobre do país.

O que doravante mudou em 1960, quando inicia a preocupação com os processos avaliativos voltados para o campo escolar, no que tange à aplicabilidade em sala de aula, aliás, esses instrumentos deveriam garantir dados daquilo que teria sido ensinado no processo de aprendizagem e ensino.

Todavia, essa nova forma de ver o processo avaliativo, foi ocorrendo e muitas vezes confundiram-se por parte de alguns professores como um instrumento que deveria ser mantido 
para manter a disciplina e a forçar os estudantes a procurar aprender.

Dessa forma, é preciso contextualizar a historicidade desse processo no Brasil, para averiguar o pensamento de avaliar na contemporaneidade, no qual Hadji (2001, p. 9), mencionou que "a noção de avaliação formativa foi proposta por Scriven, em 1967, em relação aos currículos, antes de ser estendida aos estudantes por Bloom em 1971".

Assim, essa terminologia começou a mudara partirdoano de 1970 no Brasil, entretanto, observa-se que no dia a dia da sala de aula e dos sistemas municipais e estaduais de ensino, que ainda havia resistências às mudanças das práticas da avaliação da aprendizagem escolar, fluindo práticas de caráter tradicionalista.

O aproveitamento não vem da ameaça nem do medo da reprovação, mas sim de uma orientação e/ou reorientação consistentes e constantes da aprendizagem, mediante adequados procedimentos de ensino. A proposta do "ensino por objetivos", elaborada por ele, era bem simples: com base em tarefas preestabelecidas, proceder ao ensino, servindo-se dos recursos necessários, e no processo de ensinar e aprender, em dados momentos específicos, diagnosticar se a aprendizagem se dera ou não (LUCKESI, 2011, p. 208).

Segundo Luckesi (2011, p. 207), a avaliação perfaz o caminho na qual delimita a práticas de provas e exames foram sistematizadas a partir do século XVI e XVII, para que os professores agissem com práticas autoritárias e intimidatórias, na intenção de "colocar os educandos nos eixos, sob-rígido controle".

Com esse pensamento, iniciam novas regras para serem efetivadas quando houve a aplicabilidade das avaliações que doravante eram chamadas de provas, dentre os quais deveriam haver a presença dos alunos, tempo estipulado para execução da prova, preparação, forma, cuidados com os que se sentam juntos, saída da aula, entrega das provas, assinatura do nome, conclusões da prova, tempo, apresentação aos exames (orais) (LUCKESI, 2011, p. 244-246).

Essa crescente preocupação com os desempenhos escolares dos alunos da educação básica, em sala de aula, referente a aprendizagem, desponta no final da década de 80 , no sentido de valorizar as políticas educacionais e a globalização no que tange aos aspectos econômicos, culturais e sociais por meio da ação educativa com o escopo de diagnosticar o processo de ensino aprendizagem do aluno a avaliação sistêmica.

Dessa forma, a gestão pública da educação brasileira, formula a proposta inicial de um sistema nacional de avaliação no final dos anos 80 , embora fosse objeto de interesse já na reforma dos anos 30 e estivesse presente, desde então, nos esboços de pesquisa e de planejamento educacional (AZEVEDO, 2000).

Essa primeira experiência de avaliação em larga escala deveria ser iniciada por meio da implantação de um sistema nacional de avaliação para apontar ao Estado os resultados frente aos objetivos da educação nacional.

Segundo Coelho (2008, p. 01), esse diagnóstico permitiria medir, avaliar e informar por intermédio de uma instrumentalização racional as práticas que precisavam ser reajustadas para regulação estatal e criação cultura da avaliação no Brasil.

Sendo assim, o primeiro movimento da avaliação da educação básica no Brasil decorre das avaliações educacionais do contexto internacional, quando nos anos de 1965 houve a aprovação do Primary and Secondary Education Act, e da experiência dos indicadores internacionais de qualidade da educação pela Organização para a Cooperação e Desenvolvimento Econômico - OCDE em 1970 (COELHO, 2008, p. 01).

Neste contexto, entre os anos de 1987 a 1990, o Ministério da Educação no Brasil, investiu no desenvolvimento do Sistema de Avaliação do Ensino Público de $1^{\circ}$ grau denominado SAEP, com o foco de testagem do rendimento do aluno.

Entretanto, foi na Constituição Federal de 1988 (BRASIL, 1988), que a avaliação educacional é tratada de forma associada à qualidade da educação. No art. 206, a "garantia de padrão de qualidade" figura como um dos princípios basilares do ensino. No art. 209, a avaliação da qualidade pelo poder público aparece como condição do ensino livre à iniciativa privada. Ao tratar do Plano Nacional de Educação, o art. 214 indica como um dos resultados pretendidos a "melhoria da qualidade do ensino" (BRASIL, 1988). 
Neste sentido, a avaliação sistêmica surge para ser aplicada em larga escala com a intencionalidade de regular a educação básica como estratégia para gestão do ensino.

Além disso, com a promulgação da Lei de Diretrizes e Bases da Educação nº 9394 de 20 de dezembro de 1996, instituiu-se no Art. 13, a responsabilidade dos professores diante do ato de avaliar (BRASIL, 1996).

Assim, os olhares da avaliação retomam por meio da LDBEN, o papel professoral, consistindo em cumprir a missão institucional de ensinar e posteriormente verificar o saber efetivado.

Segundo Weisz (2002, p. 94):

a chave para a construção do conhecimento é o diálogo, sem ele, o professor e o aluno representam apenas máquinas, onde cada um desempenha seu papel, sem comunicação mútua, sem a discussão de ideias e a troca de experiências. Essa troca de experiências e a conversação entre ambos também desempenha um papel importante na hora da avaliação.

Afirma-se que a escola é responsável pela formação plena de cidadãos conscientes, reflexivos de suas ações, munidos de competências e habilidades necessárias para funcionalidade futuras. Para tanto, precisa organizar um processo avaliativo qualitável do ensino aplicado.

Todavia, no ano de 2007, o Ministério da Educação lançou no dia 24 de abril, o Decreto $n^{\circ}$ 6.094/2007, que dispõe sobre a implementação do Plano de Metas Compromisso Todos pela Educação, pela União Federal, em regime de colaboração com os Municípios, Distrito Federal e Estados, e a participação das famílias e da comunidade, mediante programas e ações de assistência técnica e financeira, visando à mobilização social pela melhoria da qualidade da educação básica (BRASIL, 2007).

Seguidamente, criou-se o Índice de Desenvolvimento da Educação Básica (IDEB) no mesmo ano, através do Instituto Nacional de Estudos e Pesquisas Educacionais Anísio Teixeira (Inep), para verificação nacional de dois fatores que interferem na qualidade da educação: a) indicadores de fluxo (taxas de aprovação, reprovação e evasão), medidos pelo Censo Escolar, e b) indicadores de desempenho em exames padronizados como o Sistema de Avaliação da Educação Básica (SAEB) e a Prova Brasil.

Essas avaliações de larga escala passaram a ser efetivadas para os estudantes em todo território brasileiro como uma avaliação sistêmica e com a intencionalidade de demonstrar o panorama da educação no Brasil referente aos estudantes da educação básica.

\section{CONCEITUANDO A AVALIAÇÃO DA APRENDIZAGEM E A SISTÊMICA}

Para Libâneo (2013, p. 217), [...] a avaliação é uma apreciação qualitativa sobre dados relevantes do processo de ensino e aprendizagem que auxilia o professor a tomar decisões sobre o seu trabalho.

A avaliação contribui de modo significativo para o desenvolvimento das atividades educativas, pois a apreciação dos resultados possibilita a tomada de decisões para o enriquecimento do trabalho pedagógico e metodológico do professor.

Porém, muitos profissionais não conseguem visualizar esse processo pedagógico com outros olhares e esquecem que a prática de avaliar consiste na coleta, análise, e sistematização de um resultado no qual descreve o conhecimento do educando, bem como a ação professoral na ministração dos saberes.

Segundo Romão (2011, p. 49), avaliar não é simples e exige domínio de conhecimentos e técnicas, além de experiências de processos concretos.

O pensamento de Romão, dialoga com Méndez (2002, p. 30), quando enfatiza:

A avaliação está estreitamente ligada
à natureza do conhecimento: uma vez
esta seja esclarecida, a avaliação deve
ajustar-se a ela se quiser ser fiel e manter
a coerência epistemológica que Ihe dê
consistência e credibilidade práticas,
mantendo coesão entre concepção e as
realizações concretas.

Esses diálogos epistemológicos alicerçam a importância de ver os processos que embasam a constituição de uma avaliação, pois é preciso o entendimento que essa ação educacional deve buscar resultados significativos da assimilação dos conhecimentos adquiridos em sala de aula. 
Além disso, Vasconcellos (1998, p. 105), frisa que quando se avalia não faz o ato somente do aluno, mas faz também do currículo empregado, dos recursos didáticos, sobre as condições de trabalho, estrutura do espaço educativo.

Essa afirmativa enfatiza que ao aplicar uma avaliação o seu resultado promove o retrato estratificado da ação do saber efetivado pelos professores, o ambiente educacional e a aprendizagem dos alunos.

Dentro dessas interfaces, a avaliação surge com o conceito de verificar a concretização do currículo, da organização da gestão educacional, sendo este o documento que permite o controle sobre os indicadores da educação (LIMA, 2019, p. 25).

Sobrepujando dessa forma, que as práticas sejam formatadas por intermédio da reflexão e ruptura de paradigmas, e ao mesmo tempo com a reinvenção para avaliar o educando.

Assim, deve-se ter um novo olhar para a avaliação da aprendizagem, ressignificando seu papel na prática pedagógica e possibilitando uma ação de acompanhamento da aprendizagem do ensino ministrado e não somente um mecanismo de aprovação ou reprovação dos alunos (LIMA, 2019, p. 28).

Diante do exposto, Vasconcellos (1998, p. 83), interpõe a visão de pontos que devem ser analisados quando se avalia a aprendizagem:

- Propiciar a elaboração da síntese do conhecimento por parte do educando;

- Localizar as necessidades (seja dos alunos, do professor, da escola ou do contexto), para poder trabalhar em direção à superação;

- Dar oportunidades para os alunos refletir e tomar consciência de sua aprendizagem, de seus relacionamentos em sala, de seus processos mentais (atividade metacognitiva), autolocalizando-se;

Os aportes mencionam em seus diálogos que a avaliação subsidia as decisões sobre a aprendizagem, pois, a sua aplicação só tem sentido se existe a compreensão que o ser humano é um ser inacabado.

Assim, a avaliação em sala de aula dever ser compreendida como parte do processo de ensino e aprendizagem, que busca diagnosticar e superar as dificuldades identificadas, corrigir as falhas e estimular os alunos a assimilar o conhecimento e adquirir a sua autonomia para o exercício dos seus direitos e deveres na sociedade em que atua.

Entretanto, a avaliação sistêmica, diferentemente da executada em sala de aula deve ser entendida como a modalidade avaliativa em larga escala que é organizada e desenvolvida no âmbito dos sistemas de ensino com a finalidade de subsidiar as políticas públicas que devem direcionar a educação no país.

Trata de um mecanismo que busca informações por amostragem acerca dos processos de aprendizagem para a formulação de decisões do ensino em abrangência federal, estadual e municipal.

\subsection{Um novo olhar sobre a avaliação em sala de aula}

Os modelos pedagógicos da pedagogia tradicional, da escola nova e da tecnicista assumiram uma avaliação por meio da função classificatória, autoritária e disciplinadora, enquanto nas pedagogias libertadora, libertária e crítico-social dos conteúdos e da histórico crítica ela assumiu a função de diagnosticar o desenvolvimento dos alunos em todos os aspectos.

Ressalta-se que além da classificação é preciso enfatizar a abordagem que esclarece a diferença entre avaliar para a aprendizagem ou somente classificar o ensino adquirido pelo estudante. Sob a concepção tradicional da avaliação Perrenoud, declara:
A avaliação é tradicionalmente associada, na escola, à criação de hierarquias de excelência. Os alunos são comparados e depois classificados em virtude de uma norma de excelência, definida em absoluto ou encarnada pelo professor e pelos melhores alunos (1999, p. 11).

A ideia tradicionalista traz a avaliação na versão de práticas de exames, no qual se valoriza no aluno o cognitivo desenvolvido pelas formas de memorização e reprodução fiel do que Ihe foi ensinado, dos conteúdos fora da realidade e do contexto social, atuando os alunos como sujeitos passivos, em que o seu saber é medido por nota, o que resultará em classificação, como o aluno bom ou ruim, fato que pode levar o aluno 
a uma exclusão social e de saberes.

Hoffmann (2012, p. 18) destaca que há no seio da sociedade um comportamento de reação diante da possibilidade de se extinguir do sistema educacional a realização de provas obrigatórias.

Observa-se que as perspectivas da avaliação classificatória, ainda se fazem presentes no cotidiano escolar, sob a crença dos pais, professores e sociedade em geral que veem nessa avaliação que usar notas diz se houve o conhecimento, em que a qualidade se confunde com quantidade, e promove uma das maiores ações de desigualdades sociais e exclusão.

Diferentemente da visão classificatória a formativa visa a identificar as falhas para que 0 professor possa auxiliar da melhor forma o aluno, por intermédio de planejamentos que viabilizem a superação das dificuldades apresentadas.

Perrenoud (1993, p. 173), define a avaliação na perspectiva de que o processo:

\section{[...] ajuda o aluno aprender e o professor a ensinar. A ideia base é bastante simples: a aprendizagem nunca é linear, procedem por ensaios, por tentativas e erros, hipóteses, recuos e avanços: um indivíduo aprenderá melhor se o seu meio envolvente for capaz de lhe dar respostas e regulações sob diversas formas $[\ldots]$.}

$\mathrm{Na}$ avaliação formativa o objetivo é a regulação do processo de ensino e aprendizagem, feedback ao aluno do ensino, e ao mesmo tempo cabe ao professor fazer suas ações que permita a reflexão, análise, novas formas de avaliar e adequar o seu trabalho pedagógico o sentido de mobilizar atitudes para contribuir com o progresso.

Nas escritas de Mendez (2002, p. 62):

compreende-sequeaavaliaçãoformativa é capaz de ajudar o aluno a aprender e avançar em suas aprendizagens. Deve adotá-la como um momento de demonstração das ideias, das dúvidas, inseguranças etc. Imprescindível que ela ocorra de forma contínua, pois caso contrário se for realizada somente ao final de um processo o resultado será de classificação, seleção e exclusão, [...]".

Loch (2000, p. 31) dialoga com Mendez, quando traz a sua concepção de avaliação formativa:

Avaliar não é dar notas, fazer médias, reprovar ou aprovar os alunos. Avaliar, numa nova ética, é sim avaliar participativamente no sentido da construção, da conscientização, busca da autocritica, autoconhecimento de todos os envolvidos no ato educativo, investindo na autonomia, envolvimento, compromisso e emancipação dos sujeitos.

Avaliar um aluno atribuindo-lhe nota às vezes pode ser injusto, tem-se como proposta a avaliação emancipatória defendida por Hoffmann (2012, p. 67):

$\mathrm{Na}$ prática classificatória, a pergunta do professor "comprova" respostas que ele já antecipou. Ele explica noções e ensina como se faz e depois pergunta ou realiza tarefas para ver se a resposta do aluno está de acordo com o que ele ensinou, $\mathrm{Na}$ concepção mediadora, o professor pergunta sempre ao iniciar, ao desenvolver e ao finalizar etapas.

Apesar da avaliação formativa e emancipatória trazerem mais contribuição para as aprendizagens do aluno, nas escolas as práticas professorais vão mais de encontro com as classificatórias que versam sobre a questão conteudista, repressora, disciplinadora e punitiva, sem considerar o processo de construção dos conhecimentos e das aprendizagens.

\section{A EFETIVAÇÃO DE AVALIAÇÕES SISTÊMICAS NA REDE MUNICIPAL DE ENSINO}

A avaliação sistêmica da aprendizagem deve ocorrer com o objetivo de acompanhar o desenvolvimento educacional do aluno, e ao mesmo tempo verificar a prática pedagógica efetivada pelos professores ao ensinar.

Sendo assim, com o resultado de 4,8 de IDEB referente aos resultados do ano de 2015 , que apontava que o município estava abaixo da meta proposta de 4,9 pelo INEP, a Secretaria Municipal de Educação (SEMED) implantou a sua avaliação sistêmica denominada Avalia Porto Velho no ano de 2017.

A primeira avaliação ocorreu com a intencionalidade de alcançar melhores 
resultados no SAEB, na qual o objetivo primordial do Avalia Porto Velho é diagnosticar o processo ensino aprendizagem, e posteriormente realizar intervenções na prática do professorado com o intuito de embasar as Competências e Habilidades para elevar o índice de Desenvolvimento da Educação Básica da Rede Municipal de Educação.

Sua legitimação foi feita por meio da Portaria $n^{\circ}$ 126/ASTEC/GAB/SEMED de 13 de junho de 2017, no qual adotou na Rede Pública Municipal de Ensino de Porto Velho, a Prova Institucional. E do Decreto $n^{\circ} 14.571$ de 29 de junho de 2017, que instituiu, a partir do ano letivo de 2017, a Prova Institucional na Rede Pública Municipal de Ensino de Porto Velho.

A Avalia Porto Velho foi aplicada inicialmente para 55 (cinquenta e cinco) unidades escolares da zona urbana e 34 (trinta e quatro) da zona rural, totalizando 5.772 (cinco mil e setecentos e setenta e dois) estudantes de 237 (duzentos e trinta e sete) turmas dos $5^{\circ}$ anos do ensino fundamental.

A prova foi composta por 44 (quarenta e quatro) itens, divididas em 04 (quatro) blocos dos eixos curriculares de Língua Portuguesa e Matemática. Utilizou-se na composição dos itens os descritores da Prova Brasil, e os critérios adotados para correção foi de acertos e erros.

A unidade escolar participante, recebeu um boletim dos seus resultados no qual delineou as fragilidades do processo de aprendizagem dos estudantes participantes.

A avaliação sistêmica da Rede Municipal de Porto Velho, consubstanciou o diagnóstico dos serviços ofertados, e os resultados alcançados subsidiaram a reflexão sobre o trabalho desenvolvido, e legitimou as ações para a prática educativa.

Dessa forma, a aplicabilidade da avaliação sistêmica colaborou para pensar o ensino e buscar as premissas da qualidade educacional, e ao mesmo tempo capacitar os saberes que também serão apontados na avalição de larga escala do SAEB.

Frisa-se que $o$ ato de avaliar seja interno ou externo permite ao aluno, ao professor e ao sistema verificar o desempenho das competências e habilidades adquiridas pelos alunos resultantes da aprendizagem, bem como - resultado/diagnóstico e acompanhamento significativo do ensino.

Além disso, proporciona a tomada de intervenções pedagógicas para curto, médio e longo prazo para promoção qualitável do saber e da oferta educacional.

Demo (1995, p. 47), menciona que "para compreender a qualidade da ação educativa ao avaliar, precisa-se vincular a mesma à formação dos alunos para cidadania e vida, mediante a qualidade e competência humanizadora formalmente preparado".

\section{CONSIDERAÇÕES FINAIS}

Ao finalizar este estudo a percepção que se teve com a revisão de literatura é que falar em avaliação requer muita habilidade no trato com relação às diferenças individuais para o desenvolvimento dos alunos, visto que os seus efeitos podem causar situações prejudiciais ao desenvolvimento educacional e social dos nossos alunos, dado a possibilidade da exclusão temporária (ou definitiva).

Com respaldo nos teóricos abordados conclui-se que há de se estabelecer em nossas escolas/sala de aula práticas condizentes as teorias atuais e ao novo perfil de estudante, visto que é necessário mudar a concepção de deliberar o ensino, o currículo e as ações administrativas e pedagógicas somente por nota.

Torna-se imprescindível formar e avaliar a qualidade do ensino efetivado pelos professores ao integralizarem o saber e promover práticas pedagógicas para estabelecer a autonomia do indivíduo.

Além disso, é preciso que as avaliações sistêmicas sejam empreendidas para viabilizar políticas públicas em termos de propagar maiores investimentos, formações continuadas para os professores, melhores infraestrutura e recursos didáticos para proporcionar um ensino qualitável que promova a equidade e igualdade.

Em se tratando do problema e objetivo desta pesquisa, observou-se que a Rede Municipal de Ensino de Porto Velho com a implantação da avaliação sistêmica Avalia Porto Velho buscou obter um diagnóstico da aprendizagem ofertada e ao mesmo tempo ter um panorama a partir do ano de 2017 das fragilidades do conhecimento que estavam lacunados no desenvolvimento dos estudantes do $5^{\circ}$ ano do Ensino Fundamental de forma que alcancem competências e habilidades, e que futuramente possam realizar a avaliação externa do SAEB com os conhecimentos necessários. 
Por fim, os autores destacaram a importância dos professores, gestores e representantes educacionais observarem as novas formas de avaliar o estudante na sala de aula contemporânea, pois é preciso ver que o desenvolvimento do aluno é composto por questões de ordens cognitivas, culturais e socioemocionais.

\section{REFERÊNCIAS}

AZEVEDO, J. M. L. O Estado, a política educacional e a regulação do setor educação no Brasil: uma abordagem histórica. In: FERREIRA, N. S. C.; AGUIAR, M. A. S. (Org.). Gestão da educação: impasses, perspectivas e compromissos. São Paulo: Cortez, 2000.

BAUMAN, Zygmunt. Globalização: as consequências humanas. Tradução Marcus Penchel. Rio de Janeiro: Jorge Zhar Editor, 1999.

BRASIL. Constituição Federal de 1988. Brasília, 1988.

BRASIL. Lei de Diretrizes e Bases da Educação n 9394 de 20 de dezembro de 1996. Brasília. 1996.

\section{BRASIL. Decreto Presidencial $n^{\circ}$ 6.094,} de 24 de abril de 2007. Dispõe sobre a implementação do Plano do Plano de Metas Compromisso Todos pela Educação. Brasília. 2007.

Coelho, Maria Inês de Matos. Vinte anos de avaliação da educação básica no Brasil: aprendizagens e desafios. Ensaio: avaliação e políticas públicas em educação. v. 16, n. 59 . Rio de Janeiro. 2008. Disponível em: https:// www.scielo.br/scielo.php?script=sci_arttext\&pi $\mathrm{d}=$ S0104-40362008000200005. Acesso em: 02 de maio 2020.

\section{DEMO, Pedro. Metodologia Científica em} Ciências Sociais. São Paulo: Atlas, 1995.

HADJI, Charles. Avaliação desmistificada. Porto Alegre: Artmed Editora, 2001.

HOFFMANN, Jussara. Avaliação Mediadora: uma prática em construção da pré-escola a universidade. Porto Alegre: Mediação, 2012.

LIBÂNEO, José Carlos. Organização e gestão da escola: teoria e prática. 6 . ed. São Paulo: Heccus, 2013.

LOCH, Jussara M. de Paula. Avaliação: uma perspectiva emancipatória. Química na

Escola, n. 12. novembro, p. 31, 2000.

LIMA, Selena Castiel Gualberto. Educação Integral e a Avaliação da Aprendizagem Escolar: um estudo em uma escola de Ensino Médio de Tempo Integral no Município de Porto Velho-RO. 125 f. Dissertação (Mestrado em Educação). Universidade Federal de Rondônia - UNIR, Porto Velho: 2019.

LUCKESI, Cipriano Carlos. Avaliação da aprendizagem: Componente do ato pedagógico. São Paulo: Cortez, 2011.

MENDEZ, Juan Manuel Álvarez. A estrutura da avaliação. In: . Avaliar para conhecer, examinar para excluir. Porto Alegre: Artmed Editora, 2002.

NASCIMENTO, Maria Isabel M. A Primeira Escola de professores dos Campos GeraisPR, Tese (Doutorado). Universidade Estadual de Campinas-UNICAMP- Faculdade de Educação, 2004.

\section{NEVES, Fátima Maria. O Método} Lancasteriano e o processo de formação disciplinar do povo (São Paulo, 1808-1889). Tese (Doutorado. UNESP, Assis: 2003.

PERRENOUD, Philippe. Não mexam na minha avaliação! Para uma aprendizagem sistêmica da mudança pedagógica. In: Rdtrela, A.; NOVOA, A. Avaliações em Educação: novas perspectivas. Porto, Portugal: Porto Editora, 1993, p. 173.

PERRENOUD, Philippe. Avaliação: da excelência a regulação das aprendizagens. Porto Alegre: Artes Médicas, 1999.

ROMÃO, José Eustáquio. Avaliação dialógica: desafios e perspectivas / José Eustáquio Romão. 9. ed. São Paulo: Cortez, 2011.

VASCONCELLOS, Celso dos Santos. 
Avaliação da aprendizagem: práticas de mudança - por uma práxis transformadora. São Paulo: Libertad, 1998.

WEISZ, Telma. O Diálogo Entre o Ensino e a Aprendizagem. São Paulo: Ática, 2002.

\section{LAS PERSPECTIVAS DEL ACTO DE EVALUAR EN AULA Y LA EVALUACIÓN SISTEMÁTICA EN LA RED MUNICIPAL DE PORTO VELHO EN RAZÓN DEL SAEB}

RESUMEN: Este artículo tiene como objetivo reflexionar sobre la conceptualización de evaluación y algunos de sus aspectos históricos en Brasil, a través de un enfoque histórico-crítico basado en una revisión de literatura. Cabe destacar que, en el contexto educativo, en algunas situaciones, el acto de evaluar se realiza con el único propósito de clasificar la enseñanza, el alumno y el trabajo del docente. Además, desde el año de 2007, el Gobierno Federal ha implementado la evaluación sistémica aplicada a estudiantes de algunos años de primaria y secundaria, con el objetivo de verificar los aprendizajes y presentar el Índice de Desarrollo de la Educación Básica (IDEB) de todo el territorio brasileño. Por lo tanto, buscamos respuestas al problema respectivo: ¿cómo puede la evaluación sistémica en la Red Educativa Municipal de Porto Velho, contribuir a mejorar los aprendizajes para subsidiar la calidad de la práctica pedagógica a los estudiantes? El objetivo general de este artículo fue identificar algunos aportes de la evaluación sistémica para mejorar el aprendizaje en la Red Municipal de Educación de Porto Velho, a partir del año de 2017, bajo la responsabilidad del Departamento Municipal de Educación. La metodología utilizada se basó en el levantamiento de bibliografías con enfoque cualitativo sobre el tema. Concluimos que existe la necesidad de repensar las prácticas evaluativas en la escuela, así como en el sistema educativo municipal y federal, pues existe evidencia de que el estudiante contemporáneo presenta un nuevo perfil a formarse frente a los avances tecnológicos e innumerables problemáticas socioemocionales, lo que remite a la importancia de evaluar también al alumno en los aspectos intelectuales, físicos, culturales y emocionales.

Palabras clave: Evaluación;Aprendizaje; Calidad de la enseñanza; SAEB. 